\title{
MEETING SUMMARIES
}

\section{UNDERSTANDING LAND- ATMOSPHERE INTERACTIONS ACROSS A RANGE OF SPATIAL AND TEMPORAL SCALES}

by Pedro A. Jimenez, Jordi Vila-Guerau de Arellano, Jorge Navarro, and J. Fidel Gonzalez-Rouco

$\mathrm{T}$ here is an increasing awareness of landatmosphereinteractions (L-AI) in modulatinglocal phenomena as well as weather and climate variability at regional scales. As a result, the increasing attention that L-AI processes are receiving nowadays is not surprising. Our understanding of the biophysical processes governing these interactions is still limited, thereby hampering improvement in model parameterizations and their influence at different spatial and temporal scales.

A collaborative effort between the Research Centre for Energy, Environment and Technology (CIEMAT; Spain), the Wageningen University (WU;

AFFILIATIONS: JIMENEZ-Division de Energias Renovables, CIEMAT, Madrid, Spain, and Mesoscale and Microscale Meteorology Division, National Center for Atmospheric Research, Boulder, Colorado; VILA-Guerau de AreLlanoMeteorology and Air Quality Section, Wageningen University, Wageningen, Netherlands; NAVARRO_Division de Energias Renovables, CIEMAT, Madrid, Spain; GonZALEZ-RoucoDepartamento de Astrofisica y Ciencias de la Atmosfera, UCM, and Instituto de Geociencias, UCM-CSIC, Madrid, Spain CORRESPONDING AUTHOR: Pedro A. Jimenez, Division de Energias Renovables, CIEMAT, Avenida Complutense 40, 28680 Madrid, Spain

E-mail: pa.jimenez@ciemat.es

DOI:10.II75/BAMS-D-13-00029.I

In final form II April 2013

(C)2014 American Meteorological Society

\section{LAND-ATMOSPHERE INTERACTIONS AT THE} REGIONAL SCALE

WhAT: Scientists from 15 different countries met to update the state of the science on landatmosphere interactions considering a wide range of spatial and temporal scales and to discuss how to improve both our understanding of biophysical processes that occur at the land surface and their representation in atmospheric models.

WHEN: 8-10 October 2012

Where: Madrid, Spain

the Netherlands) and the Complutense University of Madrid (UCM; Spain) was directed to organize an international workshop to update our scientific understanding of the biophysical processes controlling L-AI, the different modeling approaches used to represent them, and the impacts that these processes and their interactions produce in the regional climate. The special format of the workshop ${ }^{1}$ with keynote lectures, posters, and large time slots dedicated to discussion facilitated the necessary interaction among the participants considering the many subdisciplines within the field. The following sections highlight the main topics covered in the

'The event was partially funded by the European Geosciences Union (EGU) and the Ministerio de Economa y Competitividad (MINECO) from the Spanish government. 
lectures, while a general overview of the workshop can be found online (http://eventos.ciemat.es/web legu/overview).

FUNDAMENTAL PROCESSES. From an observational point of view, the closure of the surface energy balance (SEB) remains the fundamental process to be understood in land-atmosphere interactions (L-AI). The net radiation at the surface is always larger than the sensible heat, latent heat, and ground heat flux. Typical residuals range from $0 \%$ to $30 \%$ and mainly take place during the day. Over homogeneous and nonvegetated surfaces, the SEB is closer to being in balance, but patchy land conditions enhance the disagreement. Secondary circulations created by the surface heterogeneity are a plausible explanation for the unbalance (Foken 2008). Understanding this fundamental problem remains a key challenge to properly evaluating the representation of surface fluxes in our atmospheric models.

Other atmospheric effects like the dryness conditions of the free atmosphere and the interaction with convectively driven turbulence in the atmospheric boundary layer (ABL) were also discussed as potential mechanisms that directly influence the evaporation rate and therefore modify the partition of sensible and latent heat fluxes at the surface. Soil, vegetation, and ABL dynamics need to be considered as an integrated system to understand key processes that affect the global energy system, like evaporation and its potential changes due to climate variability (van Heerwaarden et al. 2011). An illustrative example of L-AI using numerical modeling experiments showed that very similar evolution and magnitude of the evaporation rate led to different conditions for the formation of boundary layer clouds. Such differences stress the importance of considering the free-atmospheric conditions in the integrated system.

Tall vegetation effects were also discussed as they profoundly impact the SEB and atmospheric turbulence. Of note was how canopy-induced turbulent structures mix the canopy layers inducing changes in leaf temperatures and therefore in the radiative balance. The leaves absorb momentum through form and viscous drag and exchange heat/ moisture with the flow complicating its representation in larger-scale atmospheric models. Recent observational efforts like the Canopy Horizontal Array Turbulence Study (CHATS) are fundamental for gaining an understanding of how thermodynamic and atmospheric compounds behave in and above canopies (Patton et al. 2011), providing fundamental knowledge toward developing parameterizations representing soil-canopy-atmosphere coupling.

Closely related to this recognition of the need to couple vegetation and soil hydrology to atmospheric dynamics, it was discussed how potential climate modifications like atmospheric warming and the rise of $\mathrm{CO}_{2}$ can alter the SEB and influence the formation of shallow cumulus clouds (Vila-Guerau de Arellano et al. 2012). It was pointed out that an accurate representation of the $\mathrm{CO}_{2}-\mathrm{H}_{2} \mathrm{O}$ fluxes controlled by plant stomata is relevant to progress in our understanding of the different feedbacks between the surface and the atmosphere. Particularly, our current plant physiology models need to be examined to ensure they are able to realistically interact with the atmosphere.

\section{REPRESENTING FUNDAMENTAL PROCESSES IN ATMOSPHERIC MODELS.}

Transferring the knowledge and understanding of L-AI processes to weather and climate models occupied the second part of the workshop. Connecting with the previous lectures, the presentations focused on vegetation, urban canopy, and ice/snow effects due to the significant and rapid modification in land cover and their influence at all range of scales. Traditional parameterizations such as the turbulent mixing within the planetary boundary layer, shortwave and longwave radiation, microphysics, and the representation of the effects produced by cumulus were analyzed in relation to regional climate modeling. Other representations such as the interaction of unresolved topography with the surface wind were also shown to be of relevance to provide more realistic atmospheric simulations (Jimenez and Dudhia 2012).

Special attention was paid to analyzing the physics of land surface models (LSMs). The importance of an accurate simulation of precipitation/snow process in order to provide adequate inputs to the LSMs was recognized. Remote sensing observations of soil moisture, snow mass, and vegetation can contribute to more precise initialization of our LSMs and thus to potential improvements in operational forecasts. Examples of snow albedo and soil water freezing (Viterbo et al. 1999) emphasized the importance of process validation for model development. Community efforts for validation of current LSMs were identified as an area where researchers should concentrate on using multiyear observations to robustly characterize model performance. 
Fundamental processes in the urban canopy and its representation in the atmospheric models were discussed. Buildings introduce surface drag, generate turbulence, and modify the heat distribution at the surface through reflection. Additionally, the urban canopy differs from the vegetated canopy in that it includes a source of heat different from radiation: anthropogenic heat. These processes are incorporated in our models and thus progress can be made in understanding L-AI between the urban canopy and the ABL dynamics (e.g., Salamanca et al. 2011). Urban vegetation and urban hydrology and their interactions with atmospheric dynamics still require investigation so they can be correctly implemented in the models. It was pointed out that a precise representation of urban processes can be of help for urban planning in a changing climate. For instance, simulations can be used to optimize air quality and investigate changes in the urban climate or with energy consumption.

\section{IMPACTS OF L-AI PROCESSES IN THE} REGIONAL CLIMATE. The ability of our current atmospheric models to reproduce regional climate was thoroughly analyzed. Transition regions between dry and wet climates show that evaporation is strongly regulated by soil moisture availability. As a result, these regions are very sensitive to L-AI affecting their weather and climate. The parameterizations controlling L-AI have special relevance over these regions.

An example of a particular region sensitive to $\mathrm{L}-\mathrm{AI}$ is the Iberian Peninsula. The importance of the representation of L-AI processes became evident when the impacts that different LSMs introduce in the peninsula's climate change projections were presented. Different LSMs led to different estimations of projected changes in temperature and precipitation (Jerez et al. 2012). The possibility of using a physical ensemble to quantify the uncertainty associated with each parameterization was shown. An important issue emerged with the evaluation of the performance of climate simulations to reproduce the current climate. Gridded observations contain errors that introduce similar uncertainty to those imposed by the physics used in the models.

The influence of vegetation and land surface properties on the European climate was also discussed during the workshop. Modeling results stressed the importance of vegetation in modulating surface climate conditions at the regional and even global scales, through both radiative and nonradiative processes (Davin and de Noblet-Ducoudré
2010). Results were also presented suggesting that introducing alternative agricultural practices in Europe could mitigate the high temperature extremes reached during heat waves. As a concluding remark, it was noted that current regional climate models used to derive future climate scenarios (e.g., CORDEX intercomparison) still do not routinely incorporate land cover changes, despite the recognized importance of land cover effects at local and regional scales.

The coupling of ground soil temperature and surface air temperature was also addressed as an issue where little attention has been paid. Borehole observations and global atmospheric simulations indicate that heat storage in the ground may not be realistically simulated due to the typical placement of the zero flux depth as the bottom boundary condition in regional and global models (Gonzalez-Rouco et al. 2009). This condition artificially leads to the accumulation of energy in the top few meters of the simulated subsurface. The appropriate depth of the bottom boundary condition placement should depend on simulated time scales. In general, it should be placed at a depth large enough so as not to interact with subsurface climate.

It was agreed that limitations in our model formulations translate into uncertainties in regional modeling, which is important under climate change scenarios. To tackle this problem, the final debate of the workshop revealed the necessity of using process-oriented models combined with complete observation datasets to asses and improve current parameterizations linked to L-AI processes. In view of the multidisciplinary and multiple-scale character of L-AI, it is advisable to create research teams composed of plant physiologists, urban specialists, and soil experts, which when combined with groups of meteorologists, atmospheric chemists, and climate scientists will allow us to make progress in our understanding of fundamental processes associated with L-AI and thus enable modelers to improve our regional and global atmospheric models.

More information related to the workshop lectures can be found online (at http://eventos.ciemat.es /web/egu/agenda).

ACKNOWLEDGMENTS. The authors thank the European Geosciences Union (EGU) and the Ministerio de Economia y Competitividad (MINECO) of the Spanish government that partially funded the workshop. Special thanks to Mirian Bravo for her assistance with the logistics and administrative work and M. de la Almudena Bailador for preparing the workshop website. 


\section{REFERENCES}

Davin, E., and N. de Noblet-Ducoudré, 2010: Climatic impact of global-scale deforestation: Radiative and nonradiative processes. J. Climate, 23, 97-112.

Foken, T., 2008: The energy balance closure problem: An overview. Ecol. Appl., 18, 1351-1367.

Gonzalez-Rouco, J. F., H. Beltrami, E. Zorita, and M. Stevens, 2009: Borehole climatology: A discussion based on contributions from climate modeling. Climate Past, 5, 97-127.

Jerez, S., J. P. Montávez, J. J. Gomez-Navarro, P. A. Jiménez, P. Jimenez-Guerrero, R. Lorente, and J. F. Gonzalez-Rouco, 2012: The role of the land-surface model for climate change projections over the Iberian Peninsula. J. Geophys. Res., 117, D01109, doi:10.1029/2011JD016576.

Jimenez, P. A., and J. Dudhia, 2012: Improving the representation of resolved and unresolved topographic effects on surface wind in the WRF model. J. Appl. Meteor. Climatol., 51, 300-316.
Patton, E. G., and Coauthors, 2011: The canopy horizontal array turbulence study. Bull. Amer. Meteor. Soc., 129, 593-611.

Salamanca, F., A. Martilli, M. Tewari, and F. Chen, 2011: A study of the urban boundary layer using different urban parameterizations and high-resolution urban canopy parameters with WRF. J. Appl. Meteor. Climatol., 50, 1107-1128.

van Heerwaarden, C. C., J. Vila-Guerau de Arellano, and J. Teuling, 2011: Land-atmosphere coupling explains the link between pan evaporation and actual evapotranspiration trends in a changing climate. Geophys. Res. Lett., 37, L21401, doi:10.1029/2010GL045374.

Vila-Guerau de Arellano, J., C. C. van Heerwaarden, and J. Lelieveld, 2012: Modelled suppression of boundarylayer clouds by plants in a $\mathrm{CO}_{2}$-rich atmosphere. Nat. Geosci., 5, 701-704.

Viterbo, P., A. Beljaars, J. F. Mahfouf, and J. Teixeira, 1999: The representation of soil moisture freezing and its impact on the stable boundary layer. Quart. J. Roy. Meteor. Soc., 125, 2401-2426. 